\title{
The need for environmental competence of teachers for rational use of natural resources and environmental protection
}

\author{
Sergey Yekimov ${ }^{1, *}$, Viktoriia Nianko $^{2}$, Irina G. Ershova ${ }^{3}$, Natalya Banko $^{4}$, and Dmitriy \\ Kucherenko ${ }^{5}$ \\ ${ }^{1}$ Publishing House "Education and Science" s.r.o., Olstynska 607/1, Praha 8, 18100, Czech Republic \\ 2 Dniprovsk State Technical University ,Dnipropetrovsk region ,Kamianske, Ukraine \\ ${ }^{3}$ Southwest State University, Kursk, Russia \\ ${ }^{4}$ Kamyshin Technological Institute (branch) of the State Educational Institution of Higher Education \\ "Volgograd State Technical University",Volgograd, Russia \\ ${ }^{5}$ Federal State Budgetary Educational Institution of Higher Education "Kuban State Agrarian \\ University named after I.T. Trubilin”, Krasnodar, Russia
}

\begin{abstract}
Environmental education is one of the main tools for solving the problems of environmental management and environmental protection . In all highly developed countries, there is a tendency to develop technologies that contribute to reducing the harmful effects of human activities on the environment. The sustainable development of society and the economy in the face of growing demands for natural resources involves the careful treatment and transmission to future generations of clean air, genetic biodiversity and soil fertility. This can be achieved through the development of high-tech technologies based on environmental principles ,which largely depends on the quality of environmental education not only for specialists in the field of environmental management, but also for all people. We hold the view that environmental education has a great impact on the ability and skills of people to make decisions in accordance with environmental norms and standards. In order for environmental education to become an effective part of universal education, it is necessary first of all that every teacher has a competence in the field of ecology.
\end{abstract}

\section{Introduction}

The current development of socio-economic processes around the world is steadily linked to the problem of environmental protection. The current environmental situation around the world requires a change in the approach of each person and humanity as a whole, since everyday human activities must be carried out in harmony with the environment without harming it. In our opinion, environmental education and knowledge should play an important role in this. We count . that they should become the main guidelines for the evolutionary development of pedagogical practice and theory. 
Every year, humanity uses natural resources more and more intensively . and its activities often cause irreparable damage to the environment, disrupting the fragile natural balance.

In our opinion, in addition to politicians and environmental organizations, teachers should take part in solving the issue related to environmental protection. Since they are entrusted with an important public mission to form the younger generation of environmental awareness and environmental competence, as an integral part of professional competence.

In our opinion, it is necessary to start developing and forming ecological culture and ecological consciousness from an early age. This goal can be achieved using a comprehensive approach to the process of educating the younger generation to reflect on the role and place of a person in the world around him and to consciously interact with the external environment.

According to [1] the use of the competence approach in the educational process makes it possible to ensure the formation of students ' skills of independent solution of various problems in their professional activities based on previously acquired skills, skills and knowledge.

When using the competence-based approach in the educational process, the prerequisites for preparing the student for self-educational activities are created. Based on the previously acquired experience as a subject of their self-educational activity, the student is able to achieve the goals that the labor market and society set for him.

According to [2], the competence approach should be based on the following principles (Figure 1):

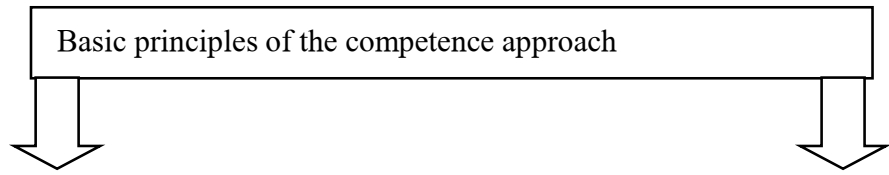

The presence of motivational, cognitive, operational-technological and behavioral components

The ability to apply experience, skills and knowledge to solve specific tasks

Fig. 1. Basic principles of the competence approach

According to [3], competence can be interpreted as one of the most significant characteristics that reflect the professional's compliance with the position held.

According to [4], competence is a good understanding, an ability based on values , abilities , and knowledge

According to [5], competence is the ability to mobilize the acquired knowledge and experience to solve a problem.

The authors [6] understand the concept of competence as knowledge structured in a certain way, skills acquired in the learning process. Competence as a product of educational activity allows you to successfully solve professional problems.

According to [7], the terms " competence "and" competence "are not completely equivalent to each other, since the" competence "consists, as a rule, of several different "competencies".

In our opinion, competence is a property of a person, which consists in the ability to use, if there is an appropriate motivation, affective and cognitive skills, as well as skills and knowledge to solve certain professional problems .

According to [5], the main competencies of a teacher are :

1) Predictive competence; 
2) Stimulating competence ;

3) Intellectual and cognitive competence

4) Organizational competence

5) Information competence

6) Diagnostic competence

7) Analytical competence

8) Evaluation and control competence.

According to [8], modern environmental education should be based on the following approaches (Figure 2):

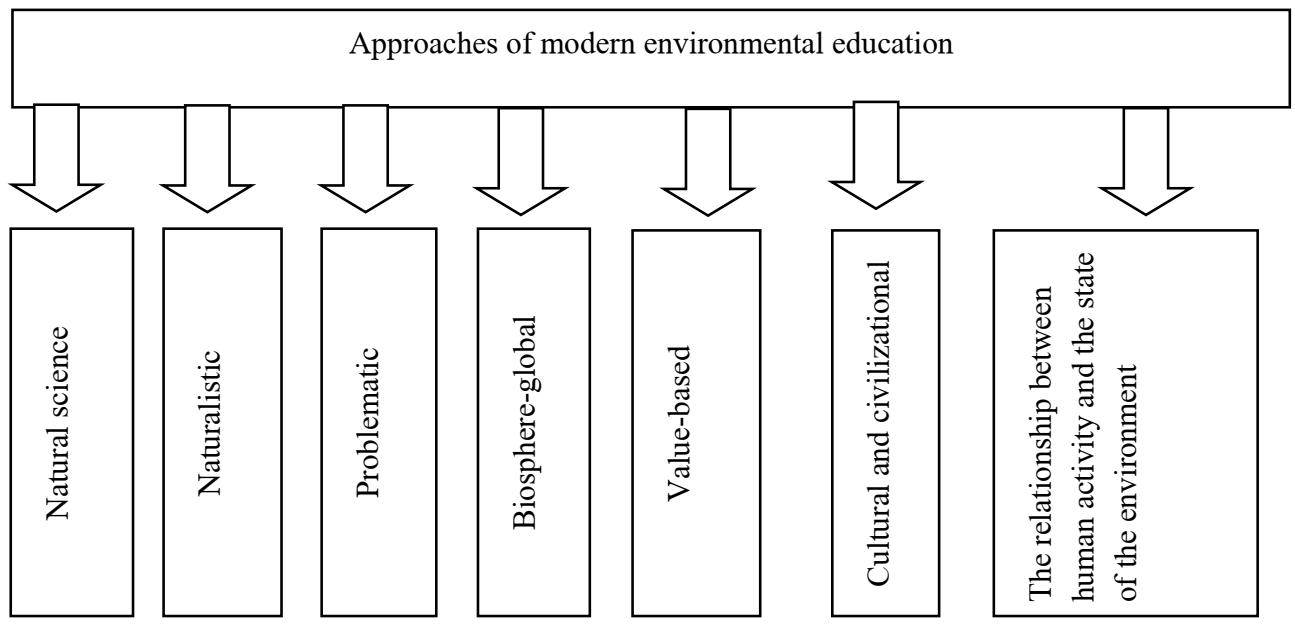

Fig. 2. Approaches of modern environmental education

\section{Methods}

In carrying out this study, the authors used an analytical method, with the help of which the studied issues were considered in their unity and development.

Taking into account the tasks and goals of the study, a functional and structural method of implementing scientific research was used.

This gave the authors an opportunity to study a number of issues related to the need for environmental pedagogues for environmental protection and rational use of natural resources.

\section{Results}

According to [9], the main components of environmental literacy of schoolchildren are:

1) Knowledge about the interaction and unity of nature and man, norms and rules of behavior in nature.

2) The ability to correctly assess the consequences of others ' and their own actions on the state of the environment.

3) Motivation to take part in roadside protection activities

4) Emotional responsiveness to the objects of the external environment and awareness of the value for a person

This in turn, in our opinion, requires the teacher to :

1) The presence of competencies about the relationship of the mental . physical and social health of schoolchildren. 
2) Possession of ecological knowledge about the place of man as a biological species in nature, and its impact on the environment.

3) Having an understanding of the value of health and a careful attitude to it.

4) Giving up bad habits

The formation of an effective level of environmental competence of citizens is an important condition for the stable socio-economic development of the state. The presence of environmental competence allows a modern person to adequately perceive the external natural environment as their habitat. Environmental competence allows you to apply your knowledge and skills in solving life and production problems based on the priority of environmental values and to understand the consequences of your actions and actions on the state of the environment.

The formation of the individual's need for independent cognitive activity about modern environmental problems, in our opinion, should become one of the main tasks facing modern education.

The need for continuous and systematic environmental education, in our opinion, requires an interdisciplinary approach.

This approach requires the coordination of the content, forms and methods of environmental education, a common logical approach and a consistent presentation of educational material.

In the modern world, a person should strive to become an environmentally-oriented subject, and his activities should be based on an understanding of environmental values.

This, in turn, requires that each teacher has an environmental competence, and an integral part of his professional competencies.

\section{Discussion}

In the educational process of training future teachers, in our opinion, it is necessary to pay more attention to environmental education.

In the process of this ecological education, a system of ideas about the environment, as a set of natural complexes and objects, should be formed. Treat them as unique and unique.

Environmental competence of the teacher, as a component of the professional competence of the teacher, is formed during the study of various academic disciplines.

Environmental competence is a psychological category that refers to the interaction of a person and the external environment.

The formation of students of pedagogical specialties of ecological culture contributes to the education of their elements of careful, responsible for the environment.

In our opinion, the formation of the ecological culture of future teachers has a great impact:

1) Continuity and systematic approach in the study of ecology

2) The unity of volitional, intellectual and emotional approaches in the educational activities of students in the process of improving the environment.

\section{Conclusions}

Environmental education is one of the main tools for solving problems of environmental protection and rational use of natural resources.

In modern highly developed countries, there is a tendency to develop technologies that contribute to reducing the harmful impact of human activities on the environment. 
The principle of sustainable development of society and the economy provides for the careful treatment and transmission to future generations of clean air, genetic biodiversity and soil fertility.

This can be achieved through the development of high-tech technologies based on environmental principles, which largely depends on the quality of environmental education not only for specialists in the field of environmental management, but also for all people.

Environmental education, in our opinion. It has a great impact on the ability of people to make decisions in accordance with environmental standards and norms.

However, in order for environmental education to become an effective part of universal education, it is necessary first of all that every teacher has a competence in the field of ecology.

\section{References}

1. A.F. Kostenko, Competence-based approach in education, Science Almanac, 85 (2014)

2. N.I. Kobseva, Bulletin of the Orenburg State University, 217, 36 (2018)

3. Aimzhan Makulova, Gaukhar Alimzhanova, Zhanar Bekturganova, Zaure Umirzakova, Laura Makulova, Kulzinat Karymbayeva, International Education Studies, 8 (2015)

4. Daina Vasilevska, Andrejs Geske, Competency-Based Approach to Educational Content for Sustainable Development in Latvia, 340 (2020)

5. M. Panteleeva, A. Sukhristina, Competency-based approach in education: russian and foreign experience, 8, 100 (2014)

6. M. Panteleeva, A. Sukhristina, Competency-based approach in education: russian and foreign experience, 8, 100 (2014)

7. Elena Andrienko, Siberian Pedagogical Journal, 44 (2020)

8. T. Olatunde-Aiyedun, Fundamentals of Environmental Education (2021)

9. William Scott, Paul Vare, Environmentally educated teachers (2020) 